\title{
Information on EFMI Working Groups
}

\author{
Rolf Engelbrecht ${ }^{1}$, Arie Hasman ${ }^{2}$ \\ 'GSF National Research Centre for Environment and Health, Munich-Neuherberg, Germany \\ ${ }^{2}$ Academic Medical Center, University of Amsterdam, The Netherlands
}

EFMI is a nonprofit organisation concerned with the theory and practice of Information Science and Technology within Health and Health Science in a European context. Its activities focus on annual conferences, MIE (Medical informatics Europe), STC (Special Topic conference), tutorials and workshops. EFMI publishes proceedings and special issues of its activities in scientific journals. It has national societies in 27 member countries in Europe. Personal members are welcome in working groups. The EFMI portal provides very actual international news and information about the use of computers in health care. http://www.EFMI.org

\section{Working Groups}

CARDS - Cards in Health Care, Social Security and Welfare

Tomas TRPISOVSKI, Prague; Claudia HILDEBRAND, Munich-Neuherberg (tomas.trpisovsky@ima.cz, hildebra @gsf.de )

EDU - Education in Health Informatics John MANTAS, Athens; Arie HASMAN, Amsterdam (jmantas@cc. uoa.gr, a.hasman@amc.uva.nl)
EHR - Electronic Health Record

Bernd BLOBEL, Regensburg bernd. blobel@ehealth-cc.de)

EVAL - Assessment of Health Information Systems

Elske AMMENWERTH, Innsbruck; Pirkko Nykanen, Tampere; Jytte Brender, Aalborg (elske.ammenwerth @umit.at, Pirkko.Nykanen@uta.fi, jytte.brender@v-chi.dk )

IPAM - Information Planning and Modelling in Health Care

Bryan MANNING, Goring-by-Sea (bryan.manning@btinternet.com)

MCMS - MDBS, Case mix and Severity of Cases

Francis ROGER-FRANCE, Brussels; Jacob HOFDIJK, Leiden (Roger@ infm.ucl.ac.be, jhofdijk@wanadoo.nl)

MICIT - Medical Informatics in Countries in Transition

Lacrimioara Stoicu-Tivadar, Timisoara; Marcelo SOSA, Madrid (stoicu@aut. utt.ro, MSosa@EuroParl. eu.int)
MIP - Medical Image Processing Alexander Horsch, Munich (alexander. horsch@imse.med.tu-muenchen.de)

NLU- Natural Language Understanding Robert BAUD; Patrick RUCH (Robert.Baud@sim.hcuge.ch, patrick. ruch@1ettres.unige.ch)

NURSIE - Nursing Informatics in Europe

Patrick WEBER, Lausanne (patrick. weber@nicecomputing.ch)

HOFMI (Human and Organisational Factors of Medical Informatics) former OIMI

Jos AARTS, Rotterdam; MarieCatherine Beuscart-Zephir, Lille (j.aarts@bmg.eur.nl, mcbeuscart@ univ-lille2.fr)

PCI - Primary Care Informatics Simon De Lusignan, London (slusigna @sghms.ac.uk )

SSE - Safety, Security and Ethics Bernd BLOBEL, Regensburg (bernd. blobel@ehealth-cc.de) 


\section{Information on EFMI Working Groups}

\author{
EFMI WG CARDS \\ Chair: \\ TomásTRIPSVSKY \\ IMAltd. \\ Insititut of Microelectronic Applications \\ Pod Vodovodem 2 CZ-15801 Praha 8 Czech Republic \\ Tel: $+420-251081022$ \\ Mobile: +420-603207900 \\ E-mail:tomas.trpisovsky@ima.cz \\ Co-Chair: \\ Claudia HIILEBRAND \\ GSF GmbH \\ Ingolstädter Landstrasse I \\ D-85764 Neuherberg \\ Germany \\ Tel: $+49893187-4182$ \\ Fax:+4989131873008 \\ E-mail:hildebra@gst.de

\section{Membership:} \\ 52 members \\ The membership is open to everyone who agrees to the WG's \\ objectives, tries to actively participate and references to the WG \\ whenever applicable \\ Homepage: hitp://MIRC.gsf.de/wgcards
}

\section{Objectives}

EFMI WG Cards aims at being a European competence centre to watch ongoing activities and to provide knowledge to policy makers and architect designers involved in the deployment of card related projects in the field of the healthcare sector.

The working group was established in December 2004 continuing the activities of Smart Card Charter TB11. TB11 documents are hosted by WG CARDS.

\section{Recentactivities}

Election of new chair persons: Paul Cheshire, Atos Origin, UK and Peter Pharow, eHealth Centre,University Clinic Regensburg, Germany

New homepage (http://mirc.gsf.de/wgcards/) has been developed and is in operation successfully.

- Repository on Cards in the Healthcare Sector has been set up Activity 2:

- Form Sheet on standardisation activities designed

- Successful EU project application (project BioHealth)

- A half-day workshop on patient involvement took place in co-operation with the MIE 2005 in Geneva, August 2005.

- CARDS was presented at Health-ID Management in Europe, Amsterdam Schiphol, 21-22 March 2006

- National Health Projects Event Budapest Feb. 2nd, 2006

Members of the WG are actively contributing to activities within

- ISO TC $215 \mathrm{WG} 4 / 5$, ISO/IEC JTC1/SC37 and SC17, ICAO

- CEN/ISSS eHealth Standardisation Focus Group

- CEN TC 251 WG III, CEN TC 224, CEN FG_Biometrics

\section{Future Adtivities}

WG meetings, presentations and workshops are planned at The Hague June 8, at ICMCC 2006, and at MIE2006 in Maastricht

- Promotion of the European Health Insurance Card

- Promoting the interoperability of the patient cards

- Promoting the introduction of Health Professional Cards in different European Countries.

- Supporting national card strategies \& projects

- Promotion of the European standardisation activities

- Supporting and contributing to conferences, tutorials and other activities on the EFMI WG's topics.

\section{Recent Publication}

C. Hildebrand, P. Pharow, H. Demski, C. Birkmann, R. Engelbrecht; Der Einsatz von Gesundheitskarten in Europa. In: Jäckel Achim (Hrsg.), Telemedizinführer Deutschland, (ISBN: 3-9808837-3-6), Ober-Möhrlen, 2005, pp. 45-48. 


\section{EFMI WG EDU}

\section{Education in Health Informatics}

Chair:
Prof.John MANTAS
Health Informatics Laboratory
University of Athens, Greece
Tel: +30 107461 1459/60
Fax: +30 107461 461
E-mail: imantas@cc.uoa.gr
Co-chair/Secretary:
Prof. Arie HASMAN
Dept. of Medical Informatics
Academic Medical Center-University of Amsterdam
Meibergdreet 15
1105 AZAmsterdam, The Netherlands
Tel: +31-205-665-184
E-mail: a.hasman@amc.uva.nl
Membership:
There is a free membership. There is not an official list of
members but those who wish to be members, in order to
facilitate the objectives of the WG, may join to the WG EDU.

\section{Objectives:}

- To organize workshops and possibly tutorials dedicated to the WG topics at each MIE conference, and other events.

- To cooperate with IMIA WG 1 regarding Recommendations about Health Informatics Curricula and other subjects involving education and training in health informatics.

- To disseminate knowledge about education and training in health informatics by various activities, such as conferences, educational events, publications and electronic means.

- To encourage individuals to publish their research and other work in journals.

- To provide a forum for discussion and debate.

\section{Recentactivities:}

Health Informatics Applications - Educational Aspects, EFMI Special Topic Conference Athens on 19-20 March 2005

Global Health Informatics Education, E. Hovenga, J. Mantas(eds.), IOS Press, Amsterdam 2004. The book identifies issues associated with the globalization of health informatics education. Members of EFMI WG on Education have participated in the publication of the book: R. Engelbrecht, A. Hasman, R. Haux, and J. Mantas.

\section{Future activities:}

- To participate in EFMI Workshops.

- To participate in MIE-STC Workshops in Education.

- To develop a database of educational programs running in Europe in Health and Medical Informatics, and attach it in the EFMI Website.

- To support Health and Medical Informatics educational and training courses, and exchange of students and teachers.

- To organise a workshop on Education at the ICICTH Samos 2006 conference 


\section{EFMI WG EHR}

\begin{tabular}{|c|}
\hline 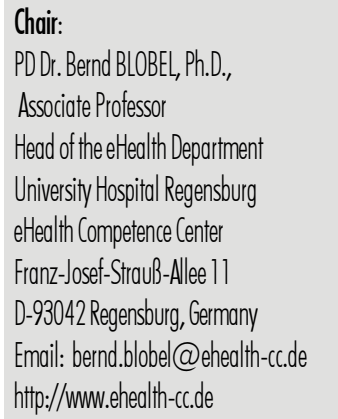 \\
\hline
\end{tabular}

\section{Objectives:}

The working group deals with the issue electronic health records in the different level of development. Such levels concern the case level, organisational level, regional level, national level, and international level. In that context, the Working Group supports

- studies on specification, implementation, and promotion of standards for EHR,

- the modelling of its architecture and its interoperability, as well as

- the education on that topic.

The EFMI Working Group "Electronic Healthcare Records" strongly co-operates with the EuroRec institute and its supporting institutions including the national ProRec Centres as well as with global EHR activities such as the openEHR Foundation

\section{Activities January 2005 - March 2006:}

- XIII Winter Course: Ambient Intelligence in Medicine AmI@Medicine, 28 February - 13 March 2005, Tenerife, Canary Islands, Spain

- EFMI Special Topic Conference 2005 "Health and Medical Informatics Applications - Educational Aspects", 5-6 March 2005, Athens

- Global standards for trustworthy, interoperable, portable health information systems and health networks including the core application Electronic Health Record, Workshop of EFMI WGs "Electronic Health Records", "Security, Safety and Ethics" and "Cards" on 6 May 2005 in Leiden, The Netherlands

- EHR Working Group Meeting during the MIE 2005 in Geneva

- Japanese German Working Conference 2005 "Continuity of Care and Communication (CCC)", 2 September 2005, Munich, Germany

- CEN/ISSS Forum, 8 November 2005, Brussels, Belgium

- Future Security Workshop: the risks, threats and opportunities, 16-17 January 2006, Sophia-Antipolis, France

- Expert Workshop "Health-ID Management in Europe - one touchstone for interoperability", 20-21 March 2006, Amsterdam, The Netherlands

- Workshop of EFMI WG "Electronic Health Records" at the EFMI STC 2006 "Integrating biomedical information: From eCell to ePatient", 7-8 April 2006, Timisoara, Romania

Additionally, national presentations and tutorials have been given by EFMI EHR WG Members.

\section{Future activities:}

Joint EHR Workshop of EFMI WGs "Electronic Health Records", "Security, Safety and Ethics" and "Cards" at ICMCC, 7-9 June 2006, The Hague, The Netherlands EHR Workshop and Working Group Meeting during the MIE 2006 in Maastricht

\section{Publications}

See an extended list at EFMI portal HYPERLINK „http://www.EFMI.org“' ' http:/ /www.EFMI.org , WG EHR 


\section{EFMI WG EVAL}

Assessment of Health Information
Systems
Chair:
Elske AMMENWERTH
UMIT - University for Health Sciences, Medical Informatics and
Technology
6060 Hall in Tyrol, Austria
E-mail: elske.ammenwerth@umit.at
Co-Chairs:
Pirkko NYKANEN
Facultyfor Information Sciences
Tampere University, Finland
E-mail: pirkko.nykanen@ @stakes.fi
Jytte BRENDER
Aalborg University, Denmark
E-mail: iytte.brender@v-chi.dk
Membership:
There is no formal membership. Interested persons are invited to
participate to the workshops and other events of the WG.The
European mailing list of the working group contains 236 members
(January2006).

\section{Objectives:}

- To foster interdisciplinary discussion on evaluation issues in health informatics.

- To support communication of experiences by organizing tutorials and workshops.

- To promote European networking on evaluation issues in health informatics.

\section{Recent activities:}

- Co-organising STC 2004 in Munich.

- Co-Editing of a Special Issue of Methods of Information in Medicine that presents selected paper from STC2004: Blobel B, Gell G, Ammenwerth E, Engelbrecht R. Contribution of Medical Informatics to Health - Meth Inform Med 2006; 45: 1-136.

- Publication of the Handbook of Evaluation Methods for Health Informatics by Jytte Brender, Academic Press, 2006, ISBN 0123704642.

- Invitation of the WG chair to present at the Usability and Human Factors Engineering Workshop in Lille, 22 - 24 May 2006.

- Conduction of the workshop on Good Evaluation Practice Guidelines at MIE 2005 in Geneva, August 2005 (details available at http://iig.umit.at/efmi).

- Editing of the section "Assessing Information Technology for Health" in the IMIA Yearbook of Medical Informatics 2006. The Declaration of Innsbruck, originally published June 2004 in the International Journal of Medical Informatics, is selected for the IMIA Yearbook of Medical Informatics 2006.

- Further work on Good Evaluation Practice Guidelines (GEP-HI) and Standards for Reporting on Evaluation Studies (STARE-HI).

- Further development of the website on "Bad Health Informatics can Kill" at http://www.umit.at/efmi, presenting examples were IT failure caused potential harm to patients.

- Further operation of a web-based Evaluation Inventory of around 1.000 abstracts of IT evaluation studies in healthcare is now made available for free at http:// evaldb.umit.at.

- Further Operation of website (http://www.umit.at/efmi) and evaluation mailing list.

\section{Future activities}

- A joint proposal for Marie Curie Training Courses on interdisciplinary IT evaluation in health care

- A workshop on publication of IT evaluation studies and on publication bias is planned for MIE 2006. 


\section{EFMI WG HOFMI}

Human and Organisational Factors of Medical Informatics), former OIMI

Chair:

Dr. Jos AARTS

Insititute of Health Policy and Management

Erasmus University Medical Center

POBox 1738

NL 3000 DR Rotterdam, The Netherlands

E-mail:|.aarts@erasmusmc.nl

\section{Co-chair:}

Dr. Marie-Catherine BEUSCART-ZİPHIR

Facultéde Médecine

Universitéde lille2

EVALAB-CERIM

1 Placede Verdun

F59045 LilleCedex, France

E-mail:mcbeuscart@univ-ilile2.fr

\section{Objectives}

- To organize workshops and tutorials dedicated to the WG topics at MIE conferences and other events;

- To establish networks of people involved in human and organizational factors of health informatics, and to learn about new developments and their activities;

- To network with related workgroups in IMIA, AMIA, IFIP and other professional organizations;

- To disseminate knowledge about human and organizational factors by various activities, such as conferences, workshops and other educational events, and publications;

- To encourage individuals to publish their research and other work in journals.

\section{Recent activities:}

Workshop and business meeting at MIE2005, Geneva.

\section{Future activities:}

- To disseminate rigorous scientific principles for performing formal usability evaluations to improve the degree of efficiency, acceptability and safety of health informatics applications.

- To support emerging teams in this field in Europe and Northern America WG HOFMI is operating jointly with its IMIA counterpart

- Workshop "Human Factors and Medical Informatics", 21-24 May 2006, Lille. http://www.univ-lille2.fr/hfeworkshop2006/

- Workshop "Integrating Sociotechnical and Usability Studies into Human Factors Engineering Approach of Designing and Implementing Clinical Systems" has been proposed for MIE2006 in Maastricht. This workshop will address the outcomes of the Lille workshop.

- Workshop about system implementation failures has been proposed for the AMIA Fall Conference in Washington, November 2006. Members of AMIA, IMIA and EFMI workgroups will be taking part in this proposed workshop.

- ITHC2007: Sociotechnical Approaches in Health Informatics, 28-30 August 2007, Sydney, Australia in conjunction with Medinfo2007. The conference cochairs are Enrico Coiera and Jos Aarts. 


\section{EFMI WG MCMS \\ Chair: \\ Prof.F.H. ROGER FRANCE, \\ Centre for Medical Informatics \\ of the University of Louvain \\ 10 av. Hippocrate, Box3718 \\ B-1200 Brussels \\ Tel: $+32-2-7644709$ \\ Fax: +32-2-7644717 \\ E-mail:roger@infm.ud.ac.be \\ Cochair/Secretary: \\ J. HOFDIJK \\ LEIDEN (The Netherlands) \\ E-mail:jhofdijik@wanadoo.nl \\ Membership: \\ No formal membership}

MBDS - Case Mix, Resource Management and Outcomes of Care

\section{Objectives}

- The organisation of special topic conferences, workshops,

- Teaching sessions in the European Region on MBDS, Case Mix and Severity of cases and their applications to Resource management and Outcomes of care.

- The communication of up to date experiences and/or references between members, including national uniform data sets, terminology, coding system and patient classification methods for resource management and quality of care.

- The dissemination of results about informatics tools and telematics systems in this specific area among EFMI and IMIA affiliated members and participants to their meetings.

\section{Recent activities}

Workshop on Case Mix and Nursing, MIE2005 Geneva, Switzerland.

\section{Future activities}

Workshop "Towards Minimum Basic Data Sets from the Electronic Patient Records for Healthcare and Clinical Management", MIE2006 Maastricht (the Netherlands):

\section{Recent Publications}

F.H.Roger France, Case Mix use in 25 countries : a migration success but international comparisons failure, International Journal of Medical Informatics 2003, $70,215-219$ 


\author{
EFMI WG MICIT \\ Medical Informatics in Countries in \\ Transition \\ Chair: \\ Lacramioara STOICU-TIVADAR \\ Professor \\ Faculty of Automation and Computers \\ University "Politehnica" Timisoara \\ Bd. V. Parvan2 \\ 300223, Timisoara, Romania \\ Tel: +40256403234 \\ E-mail:lacramioara.stoicu-tivadar@aut.upt.ro

\section{Co-chair} \\ Dr. Marcelo SOSA-IUDICISSA \\ Principal Administrator, Public Health \\ Policy Department A-Economy and Science, Internal Policies DG \\ The European Parliament \\ Rue Wiertz 60 - ATRO-K-66 \\ B-1047 Brussels, Belgium \\ Tel: +3222841776(direct) \\ E-mail:MSosa@europarl.ev.int \\ Homepage: http://uww.EFMl.org
}

\section{Objectives:}

- To promote exchange of information between actors in Europe, developing regions and world-wide, for improved access and use of data and knowledge.

- To investigate the needs, opportunities and obstacles for health information systems, informatics and telematics in developing regions.

- To disseminate European and world-wide results and experiences across developing regions and professionals

- To facilitate access to European groups and their facilities and outcomes by students, medical practitioners, nurses, health managers and any other person from developing regions interested in learning and working together with partners in Europe and other industrialised countries

- To review and select from different education options for the medical informatics domain from a range or experiences at European level and suggest the best for the situation of countries in transition.

\section{Recent Activities:}

May 2005: organizing an invited session at the CSCS15 Conference in Bucharest, Building Bridges Between Healthcare and Engineering, 25-27 May 2005, pp. 180-206. The discussions after presentations comprised issues regarding the communication between medical staff and technical staff, what is characteristic to a country in transition and what is common with EU countries.

August 2005: Geneva: EFMI \& IMIA Workshop: Health informatics in a transnational context - Exchanging experiences \& finding solutions

The WS consisted of short presentations about health informatics from different perspectives in different countries, followed by exploration of the key issues. This approach from Lacramioara Stoicu-Tivadar (EFMI) and Jean Roberts (IMIA) intended to seek views on any/all of the major points raised. Views were gathered from both developed and (re)emerging countries; from commercial, academic and operational perspectives. The intention was to facilitate discussion and a rolling set of key issues on the EFMI/IMIA website in due course. In the near future a statement/commentary on where actions can be carried out under the aegis of EFMI/IMIA in order to move a little closer towards equity of informatics in support of health overall will be produced.

\section{Future Adivities:}

Workshop at CONTI Conference, June 2006 (communication between engineers and clinicians).

Workshop at MIE2006, Maastricht, August 2006 (continuing the open subjects at MIE2005). 


\section{EFMI WG MIP}

\section{Medical Image Processing}

Chair:

Prof.Dr. Alexander HORSCH

Dept. of Medical Statistics and Epidemiology

Munich University of Technology

Ismaninger Str. 22

D-81675 Munich, Germany

E-mail:alexander.horsch@tum.de

Dept. of Clinical Medicine \& Dept. of Computer Science

University of Tromso

N-9037 Tromso, Norway

E-mail:horsch@cs.uit.no

\section{Co-chairs:}

Dr. Thomas WITTENBERG

Fraunhofer Institute for Integrated Circuits IIS

Dept. of Image Processing and Medical Engineering

Am Wolfsmantel 33

D-91058 Erlangen, Germany

E-mail:wbg@iis.thg.de

Dr. Vytenis PUNYS

Image Processing \& Analysis Lab

Computational Technologies Centre

Kaunas University of Technology

Studentu 56-304

LT-51424 Kaunas, Lithuania

E-mail:ytenis.punys@ktu.lt

\section{Membership}

There are at the moment 44 persons in the list of members and interested persons of the working group, coming from academia, industry and organizations in various different countries: Austria, Cyprus, Zech Republic, Denmark, Finland, France, Germany, Lithuania, Poland, Spain, Switzerland, The Netherlands, USA, UK.

Homepage: http://www.efmi-wg-mip.net.

\section{Objectives}

The EFMI Working Group on Medical Image Processing is primarily interested in the support of communication and common attempts of academia and industry to increase quality of innovation, research and development in the field of medical image processing. In particular, the WG has the objectives:

- To establish a reference image database for medical image processing research and development groups within the EFMI member countries

- To establish a web-based information system for European image processing groups and their current activities

- To create and maintain a working group website providing public information and (in a protected sub-area) WG-internal documents and work plans

- To organize and conduct workshops dedicated to the WG topics at the MIE conferences and other events

- To build and maintain close relationship with persons, groups, organizations and standardization bodies working on the MIP field and medical domains involved

The intense discussions with the NIH and with imaging and pharmaceutical industry about the potentials of validation platforms including image databases and strategies for their implementation have been continued during the last year. The NIH now, after large investment and several years of consensus process started to release lung CT datasets. The US experience shows the tremendous efforts needed to create reference image data. Substantial resources are mandatory, and the most promising way to go is Public Private Partnership (PPP). Recent WG workshops at CARS (Computer Assisted Radiology and Surgery) 2005 in Berlin and MIE 2005 in Geneva have also shown very clearly that there is little chance to create completely new organizational structures for the goal of pushing the establishment of validation platforms. Instead, the appropriate associations representing industries and academia shall be the next addressees of promotion and acquisition activities. This is on the agenda of the working group.

Recent and future activities include the organization of workshops and business meetings, especially at MIE, Medinfo and CARS conferences. The next workshop and working meeting will take place in June 2006 in the framework of Tromsø Telemedicine Conference TTeC 2006. Comprehensive information on the working group, its activities and their results can be found on the website. 


\section{EFMI WG NLU}

Natural Language Understanding
Chairs:
Dr.Robert Baud
Serviced'Informatique Médicale
HôpitauxUniversitairesde Genève
CH-1211 GENEVA 14 Switzerland
E-mail: Robert:Baud@sim.hcuge.ch
Patrick Ruch
Serviced'Informatique Médicale
HôpitauxUniversitaires de Genève
CH-1211 GENEVA 14 Switzerland
E-mail: Patrick.Ruch@sim.hcuge.ch
Membership:
There isno formal membership for NLL. Interested personsare
invited to contact the chairpersons and to participate to the
workshops and other events of the WG.

\section{Objectives:}

- To organize workshops dedicated to the WG topics at each MIE conference, and other events.

- To organize special topic conferences on Natural Language related subjects.

- To have personal connections with people involved in NLP in the medical domain, especially in Europe, and to learn about their current developments and activities. To develop connections with experts in the general NLP domain and to participate to related events (ACL, COLING...).

- To represent EFMI at IMIA WG6; to represent EFMI at AMIA new SIG on NLP; to represent EFMI at MEDINFO; to represent EFMI at AIME. In general, to participate to events of those entities.

- NLU is very important today for medical applications. The following trends have to be highlighted and may drive future developments in the future:

- Formal ontologies - or at least more professional criteria in this discipline - are emerging as a necessary condition for the development of domain supporting ontologies in the future,

- Multilingual developments are progressively taking place and Europe is quite a favourable location for promoting such initiatives. Future EU-funded projects on this topic are expected.

- A close cooperation between IMIA WG6 and EFMI NLU has already shown that scientific progresses are better obtained by joint efforts than individual initiatives!

\section{Recentactivities}

- The IMIA WG6 conference has taken place in Rome in April 2005 with most of the leading persons in the domain of medical ontologies. The interactions were strong and the benefits for the participants were considerable. A number of papers have been published since this event.

- A workshop has taken place in MIE 2005. In addition, two tutorials concerning NLU activities were given.

- The NoE SemanticMining by its WG20 has setup an interchange format for multilingual medical lexicon and after validation of the procedure will open it to any interested person in Europe and elsewhere. The WG NLU is actively represented in this initiative.

- A workshop about ontology representation during the STC 2006 in Timisoara, Romania.

- A workshop about "acquiring and representing multilingual, specialized lexicons: the case of biomedicine" at the LREC Conference in May 2006 in Pisa, Italy.

\section{Conclusion}

NLU is very important today for medical applications. The following trends have to be highlighted and may drive future developments in the future:

Formal ontologies - or at least more professional criteria in this discipline - are emerging as a necessary condition for the development of domain supporting ontologies in the future,

Multilingual developments are progressively taking place and Europe is quite a favourable location for promoting such initiatives. Future EU-funded projects on this topic are expected.

A close cooperation between IMIA WG6 and EFMI NLU has already shown that scientific progresses are better obtained by joint efforts than individual initiatives! 


\section{EFMI WG NURSIE}

\section{Nursing Informatics in Europe}

Chair:

Patrick Weber

Nice Computing

DeMaillefer 37

CH-1052 Le Mont-sur Lausanne Switzerland

Tel.: + 41/21/641.04.20

Fax. $+41 / 21 / 641.04 .29$

E-mail:patrick.weber@nicecomputing.ch

Co-Chair:

PDDr Thomas Buerkle

Lehrstuhl für Medizinische Informatik

Universität Erlangen

Krankenhausstraße 12

D-91054 Erlangen Germany

Tel: + 4991318526790

Fax + 4991318526754

E-mail:thomas.buerkle@imi.med.uni-erlangen.de

\section{Secretary:}

Mrs. Janette Bennett

2 Elmington Cottages

Elmington nr Oundle Peterborough PE85JZ

United Kingdom

E-mail:janette.bennett@bt.com

\section{Membership:}

Today 13 country members and 7 associate members compose the working group.

Homepage: http://www.nicecomputing.ch/nieurope/

\section{Objectives:}

- To support nurses and nursing organizations in the European countries with information and contacts and the field of informatics

- To offer nurses opportunities to build contact networks within the informatics field. This could be accomplished by arranging sessions, workshops and tutorials in connection with the Medical Informatics European (MIE) conferences or by arranging separate meetings.

- To support the education of nurses with respect to informatics and computing.

- To support research and developmental work in the field and promote publishing of achieved results.

\section{Recentactivities:}

- MIE2005, Geneva: Active participation of many members for scientific presentations, workshops.

- ENI2005, Zürich European Nursing informatics conference where members had active participation in scientific presentations.

- Nursing and Informatics for the 21st Century: an international look at practice, trends and the future, Charlotte A. Weaver, Connie White Delaney, Patrick Weber, Robyn L. Carr (Eds.), Himms 2006

- Several country members are directly involved into developments corresponding to our aims please look at country reports on the

- Detailed country reports from Switzerland, Finland, Germany, Ireland on the WG web pages

\section{Next activities:}

MIE2006, Maastricht, workshop and tutorial 


\section{EFMI WG PCI \\ Primary Care Informatics \\ Chair: \\ Dr Simon DE LUSIGNAN (2002-) \\ Primary Care Informatics \\ Division of Community Health Sciences \\ St. George's Hospital Medical School \\ LONDONSW170RE, UK \\ Tel: +442087255661 \\ Fax: +442087677697 \\ E-mail:susigna@sgul.ac.uk \\ Homepage: http://www.EFMl.org}

\section{Objectives}

The Primary Care Informatics Working Group (WG PCI) aims to promote the development of this emerging scientific discipline [1,2]. In particular, to develop the core generalisable theory that should underpin it. The group aspires to promote good practice, professionalism and the development of primary care informatics as a scientific discipline, within EFMI.

\section{Recent Activities}

Sheila Teasdale, also a working group member, published a review of the primary care informatics literature; an extremely useful reference resource for students of primary care informatics [3].

The working group has had an excellent year. We held a stimulating workshop at MIE 2005 in Geneva The principal outcome of our discussion was that there should be a move away from defining data quality in mathematical terms (e.g. completeness, accuracy, currency) and a move towards a more functional definition of "fit for purpose." Out of this meeting came an invitation to speak and participate in an international informatics meeting held in Turkey in April 2006.

\section{Future Adtivities}

We have a primary care day planned for Sunday August $27^{\text {th }}$ prior to the opening of MIE2006 in Maastricht. This day is being organised by colleagues from the Netherlands who will be showcasing their primary care systems and how routine data are made available for research.

The group is also involved in the planning of the 2008 STC. We also have plans to help organise with colleagues in IMIA and AMIA primary care informatics working groups a one day workshop prior to MEDINFO 2007 due to be held in Brisbane, Australia. This has been set for Friday $17^{\text {th }}$ August just prior to the commencement of the conference. The aim is to repeat the success of our previous one day consensus conference held prior to MEFINFO 2004 in San Francisco [4].

\section{Publications}

[1] de Lusignan S. What is primary care informatics? J Am Med Inform Assoc 2003;10(4):304-9.

[2] de Lusignan S. Introduction to the Primary Care Informatics Working Group of the European Federation for Medical Informatics (EFMI). Informatics in Primary Care 2003;11(3):175-6.

[3] Teasdale S. A review of Primary Care Informatics: past progress, present reality, future prospects. In Eds. Haux R, Kulikowski C. Yearbook 05 of Medical Informatics. Stuttgart: Schattauer; 2005. p. 139-47.

[4] de Lusignan S, Teasdale S, Little D, Zapp J, Zuckerman A, Bates D, Steele A. Comprehensive computerised primary care records are an essential component of any national health information strategy: report from an international consensus conference. Informatics in Primary Care 2004:13(4):255-64. 


\section{EFMI WG SSE}

Security, Safety and Ethics
Chair:
PD Dr. Bernd BLOBELL,Ph.D.,Associate Professor
Head ofthe eHealth Department
University Hospital Regensburg
eHealth Competence Center
Franz-Joset-StrauB-Allee 11
D-93042 Regensburg,Germany
E-mail: bernd.blobel@ehealth-cc.de
hitrp://www.ehealth-cc.de

\section{Objectives:}

To speed up the use of ICT for health care increases the challenge for trustworthiness, security and safety of solutions and infrastructure deployed.

To promote development, education and training on the field of security and privacy in health.

\section{Recent activities:}

- Common Workshop of EFMI WGs "Electronic Health Records", "Security, Safety and Ethics" and "Cards" on 6 May 2005 in Leiden, The Netherlands, titled "Global standards for trustworthy, interoperable, portable health information systems and health networks including the core application Electronic Health Record"

The event sponsored by the German HL7 User Group and HL7 Inc. (USA) has been organised within the framework of the first HL7 Working Group Meeting outside North-America. The EHR-related exchange of know-how between HL7 activists, EFMI experts and representatives from ISO and CEN has been highly evaluated.

- Tutorial " MERGEFIELD „Tutoriaux“ Security Requirements and Solutions in Distributed Health Information Systems and Health Networks" at the MIE 2005 in Geneva, Switzerland

- Working Group Meeting of EFMI WG "Security, Safety and Ethics" during the MIE 2005 in Geneva

- Session Keynotes at the IMIA WG "Security in Health Information Systems" Working Conference "Secure eHealth - Managing Risks to Patient Data", 2729 April 2006, Dijon, France

\section{Future activities:}

- Tutorial on "Security Requirements and Solutions in Distributed Health Information Systems and Health Networks" at the MIE 2006 in Maastricht in cooperation with IMIA WG "Security"

- Joint Workshop of EFMI WGs "Electronic Health Records", "Security, Safety and Ethics" and "Cards" at ICMCC, 7-9 June 2006, The Hague, The Netherlands

- Working Group Meeting of EFMI WG "Security, Safety and Ethics" during the MIE 2006 in Maastricht, The Netherlands

- Tutorial "Distributed Health Information Systems and Health Networks: Architecture, Policies, Models, Security and Privacy Requirements and Solutions" at the MIE 2006 in Maastricht, The Netherlands

\section{Publications:}

See an extended list at EFMI portal http://www.EFMI.org, WG SSE 